\title{
CLINICAL CHARACTERISTICS OF ULCERATIVE COLITIS IN NEPALESE POPULATION: EXPERIENCE FROM A TERTIARY CARE CENTER TUTH, KATHMANDU, NEPAL
}

\author{
Shaneel Harsh, Ananya Adhikari, Rahul Pathak, Prem K. Khadga, \\ Sashi Sharma
}

\begin{abstract}
Background and Aim: Rising incidence and prevalence of ulcerative colitis (UC) had been observed in Asian countries. We conducted a study in our center, aiming to describe the demographic and clinical characteristics of UC in Nepalese population.
\end{abstract}

Method: This is a cross sectional study of patients with diagnosis of UC in our hospital from Feb 2014 to Jan 2015. The diagnosis of UC has to satisfy the internationally accepted criteria. All patients were Nepalese and Clinical and epidemiological data were obtained and analysed through SPSS version 20.

Results: 60 patients were included in the study. Mean age at diagnosis was 34.6 years. Male had slight preponderance with M:F (1.06:1). Mean duration of disease at diagnosis was 3.7 years. $83 \%$ had rectal bleed, Diarrhoea was seen in $77.3 \%$,Tenesmus and Urgency in $70 \%$, Mucus in stool was found in $65 \%$, abdominal pain in $55 \% .16 .7 \%$ had weight loss and extraintestinal manifestations whereas fever was seen in $8.3 \%$. In our patients $38.3 \%$ had ulcerative proctitis and $50 \%$ had left-sided UC, whereas $11.7 \%$ had extensive UC at presentation. The majority presented with mild $(53.3 \%)$ or moderate $(38.3 \%)$ disease activity, only $8.3 \%$ with severe disease.

Conclusions: The peak age of UC was similar to other Western and Asian countries but second peak reported in western countries have not been seen in this study. This finding is similar to reports from East Asia. Similarly the proportion of patients with extra intestinal manifestations was low in our study as compared to studies reported from western world. Our study also showed that it takes longer to diagnose UC in Nepal. This might be related to the unawareness of the patients' and lack of availability of the diagnostic resources.

\section{Key Words: Ulcerative Colitis, Epidemiology, Nepal}

\section{INTRODUCTION}

Ulcerative colitis (UC) is an inflammatory disorder of the colon of unknown etiology. UC begins in the rectal mucosa, extends proximally to involve varying portions of the bowel, and has a variable clinical course; including unpredictable relapses and remissions. It is a worldwide disorder with significant geographical heterogeneity, the highest prevalence rates having been reported from Northern and Western Europe and North America. ${ }^{2}$ A significant North-South gradient has also been observed in the prevalence of the disease, with rates being higher in Northern countries. 
Ulcerative colitis has been viewed from various studies in the past as being rare in developing countries of the world, including Asia. However, recent epidemiological experience is changing these premises. The reason for this rising trend is not clear.

Although it may be related to the improved physician awareness of UC and better availability of diagnostic modalities, many people attribute this to the increasing affluence of many Asian countries leading to Westernization of lifestyle and changing of eating habits. This hypothesis of westernization leading to UC is supported by the strongest evidence which comes from epidemiological studies of Asian immigrants to Western countries. For instance, Chinese immigrants to Canada have been found to have higher incidence of UC than people in Hong Kong. Similarly, first-generation Indian immigrants to the United Kingdom have higher chance of developing UC than people in India.

Despite the rising incidence and prevalence of this condition in Asian countries, the data regarding this disease in Nepalese patients with UC are relatively few or none and it may be different from our Western counterparts. So, we conducted this study in our centre, aiming to describe the clinical characteristics and natural history of Nepalese patients with UC.

\section{MATERIALS AND METHODS}

All patients presenting with Ulcerative Colitis to the Outpatient department or admitted in the Department of Gastroenterology, Tribhuvan University Teaching Hospital, and Kathmandu in the study period of one year (Feb 2014 to Jan 2015) were included in the study.

UC was definitively diagnosed in those who met all 3 of the below criteria used for determining UC:
(1) A typical history of diarrhoea or blood and pus in the stool, or both, for longer than 4 weeks;

(2) A typical sigmoidoscopic or colonoscopic picture with diffusely granular, friable, or ulcerated mucosa without rectal sparing or skip lesions of characteristic continuous ulcerated mucosa; and

(3) Characteristic histopathological signs of inflammation on biopsy.

The following data from each patient were retrieved for analysis:

(i) sex (ii) age at diagnosis (iii) duration of disease (iv) presenting symptoms (v) smoking status (vi) family history of UC (vii) extent of colitis (viii) severity of disease at diagnosis (ix) extraintestinal manifestations. Extent of colitis was assessed by the first-time colonoscopy and was classified as ulcerative proctitis (E1), leftsided UC (E2), and extensive UC (E3) according to the Montreal classification of IBD.The disease severity was classified clinically according to Truelove and Witts criteria as mild, moderate, severe and fulminant colitis.

\section{Statistics}

All the data were collected as per standard prespecified Performa and all statistical analysis were performed with Statistical Package for Social Sciences version 20.0 software.

\section{RESULTS}

60 patients had been managed in the Department of Gastroenterology during the study period. All of them were Nepalese. 31 patients were male and 29 patients were female. (M: $F=1.06: 1)$. The mean age at diagnosis was 34.6 years with standard deviation of 12.7 years. 


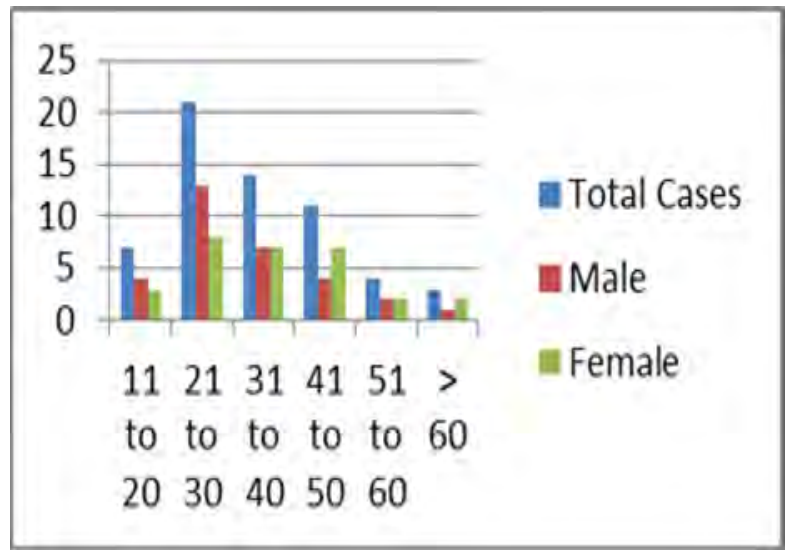

Fig. 1: Demographic distribution of Patients according to the age

The mean duration of illness at diagnosis was 3.7 years and standard deviation of 4.87 years. $88.3 \%(n=53)$ of the patients had per rectal bleed and $77.3 \%(n=44)$ had Diarrhoea as their presenting complain. Other complains like tenesmus and urgency were present in $70 \%$ (42), Mucus in stool 65\% $(n=39)$, Abdominal Pain in 55\% ( $\mathrm{n}=33)$, Weight Loss in $16.7 \% \quad(\mathrm{n}=10), \quad$ Extra Intestinal Manifestation in $16.7 \% \quad(n=10)$, and Fever was seen only in $8.3 \%(n=5)$

\section{Table: 1 Symptoms at Diagnosis}

$\begin{array}{ll}\text { Symptom } & \text { No. }(\mathbf{\%}) \\ \text { Rectal bleeding } & 53(88.3) \\ \text { Diarrhoea } & 44(77.3) \\ \text { Tenesmus } & 42(70.0) \\ \text { Urgency } & 42(70.0) \\ \text { Mucoid stoo } & 139(65.0) \\ \text { Abdominal pain } & 33(55.0) \\ \text { Weight loss } & 10(16.7) \\ \text { Fever } & 05(8.3)\end{array}$

At presentation $38.3 \% \quad(n=23) \quad$ had proctosigmoiditis, $50 \% \quad(\mathrm{n}=30) \quad$ left sided colitis and pancolitis was seen in $11.7 \%$ $(\mathrm{n}=7)$.

$53.3 \%$ patients had mild disease, $38.3 \%$ and $8.3 \%$ presented with moderate to severe disease. $3.33 \%(n=2)$ had to undergo surgical therapeutic colectomy.

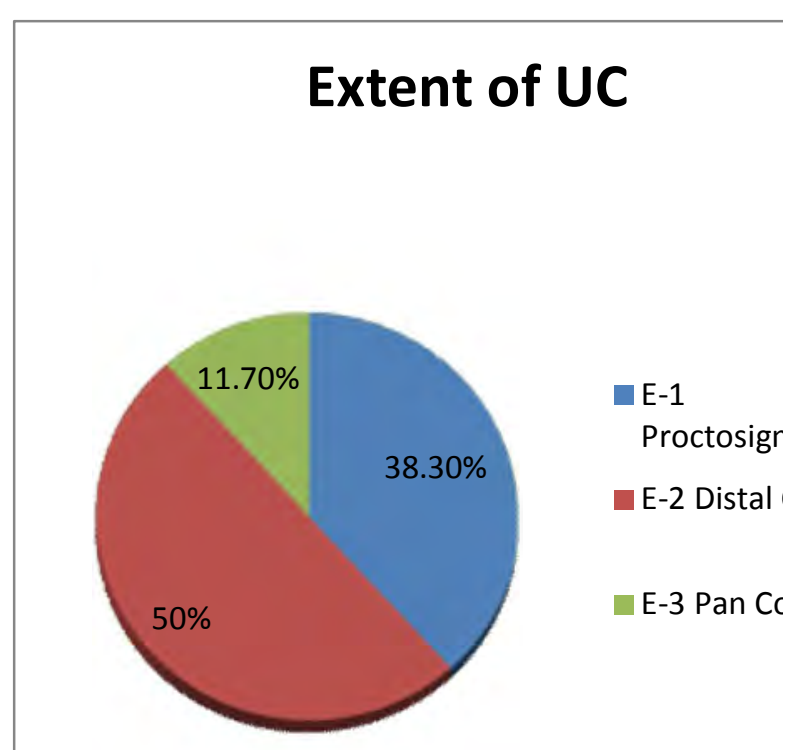

IMAGE 2: Extent of disease

At presentation Positive family history was seen in only $1.66 \%(\mathrm{n}=1)$ and this was present in his first degree relative (sister). $10 \%$ (6) of the patients were current smoker whereas $13.33 \%$ (8\%) were ex-smokers.

Majority $(86.7 \%)$, of the patients had clinical course of Chronic Intermittent type .Other two types were present with Chronic Continuous in 10\%) and Acute Fulminant in $3.3 \%$.

\section{DISCUSSION}

Ulcerative colitis should no longer be considered as a disease of Western countries. A number of studies showed that there is a rising prevalence of this disease across Asian countries.

The present study identified few important pieces of demographic information. The peak age of onset for UC was similar but in comparison to reports from western countries there was no bimodal distribution seen. This finding had similarity with the Chinese study from Hongkong 20,21,22

There is slight male preponderance $(\mathrm{M}: \mathrm{F}=$ 1.06:1). The presence of a family history for UC in our study was found to be lower than that reported from western countries and only few patients were smokers (current smokers 
$10 \%$, ex-smokers $13.3 \%$ ). Both of these data are similar to reports from China and Turkey but still does not have an appropriate explanation. ${ }^{22,23}$

In this study Extra-intestinal manifestations was found to be present only in $16.6 \%$, which is similar to other Asian studies but far less than reported in studies from the Western countries ( $>50 \%$ patients in one study). ${ }^{24,25,26 \text {, }}$

The extent of disease in this study was not different from the previous studies of Asia and Western countries.$^{20}$ Along with this other clinical features like blood in stool ,mucus in stool, abdominal pain, tenesmus, urgency, abdominal pain also very much similar to western reports. ${ }^{27}$ But not a single patient in this study had constipation which differs from reports of our western counterpart and this findings resembles the reports from east asia. ${ }^{28}$

Another significant result of this study is the relatively longer times of untreated disease of UC. Mean duration of disease at diagnosis was 3.7 years. There may be several explanations for this fact. First, non-specific initial symptoms of UC might be underrated by the patients. Secondly, higher prevalence of infectious diseases and common disorders such as haemorrhoids may have resulted in misdiagnosis of the disease. Thirdly, the negative attitudes of patients towards endoscopic procedures and lack of availability of the diagnostic facilities might also have resulted in the delay of the diagnosis.

\section{CONCLUSIONS}

The peak age of UC was similar to other Western and Asian countries but second peak reported in western countries have not been seen in this study. This finding is similar to reports from East Asia. Similarly the proportion of patients with extra intestinal was low in our study as compared to studies reported from western world.

Our study also showed that it takes longer to diagnose UC in Nepal. This might be related to the unawareness of the patients' and lack of availability of the diagnostic resources.

\section{References}

1) Katz J. The course of inflammatory bowel disease. Med Clin North Am. 1994;78:1275-1280.

2) Whelan G. Epidemiology of inflammatory bowel disease. Med Clin North Am1990;74: 2

3) Farrokhyar F,Swarbrick ET,Irvine EJ A review of epidemiology studies in inflammatory bowel disease. Scand J Gastroenterol 2001;36:2-15.

4) Loftus EV, Schoenfeld P, Sandborn WJ. The epidemiology and natural historyof Crohn's disease in population based patient cohort from $\mathrm{N}$ America: a systematic review. Aliment Pharmacol Ther 2002;16:51-60.

5) Yang SK, Edward Loftus Jr, Sandborn William J. Epidemiology of Inflammatory bowel disease in Asia. Inflamm Bowel Dis 2001;7:260-70.1-12.

6) Hossain J, Al-Faleh FZ, Al-Mofleh I, et al. Does ulcerative colitis exist in SaudiArabia? Analysis of thirty-seven cases. Saudi Med J 1989;10:360-62

7) Chuan H, Freeman HJ. Ulcerative colitis in the Chinese population of Vancouver, British Columbia. Can. J. Gastroenterol. 1994; 8: 303-7.

8) Probert CS, Jayanthi V, Pinder $D$ et al. Epidemiological study of ulcerative proctocolitis in Indian immigrants and the indigenous population in Leicestershire. Gut 1992; 3: 687-93.

9) Yang SK, Hong WS, Min YI, et al. Incidence and prevalence of ulcerative colitis in the SongpaKangdong District, Seoul, Korea, 1986-1997. J Gastroenterol Hepatol. 2000;15:1037-1042.

10) Tysk C, Jarnerot G. Ulcerative proctocolitis in Orebro, Sweden. A retrospective epidemiologic study, 1963-1987. Scand J Gastroenterol. 1992;27:945-950.

11) Garland CF, Lilienfeld AM, Mendeloff AI, et al. Incidence rates of ulcerative colitis and Crohn's disease in fifteen areas of the United States. Gastroenterology. 1981;81:1115-1124.

12) Binder $\mathbf{V}$, Both $\mathbf{H}$, Hansen $\mathbf{P K}$, et al. Incidence and prevalence of ulcerative colitis and Crohn's disease in the County of Copenhagen, 1962 to 1978. Gastroenterology. 1982;83:563-568

13) Satsangi J, Silverberg MS, Vermeire S, Colombel JF. The Montreal classification of inflammatory bowel disease: controversies, consensus and implications. Gut 2006; 55: 749-53.

14) Truelove SC, Witts LJ. Cortisone in ulcerative colitis. Final report on a therapeutic trial. BMJ 1955; 2: 1041-5. 
15) Ouyang Q, Tandon R, Goh KL et al. The emergence of inflammatory bowel disease in the Asian Pacific region. Curr. Opin. Gastroenterol.2005; 21: 408-13.

16) Jiang XL, Cui HF. An analysis of 10218 ulcerative colitis cases in China. World J. Gastroenterol. 2002; 8: 158-61.

17) Jiang L, Xia B, Li J et al. Retrospective survey of 452 patients with inflammatory bowel disease in Wuhan city, central China. Inflamm.Bowel Dis. 2006; 12: 212-17.

18) Yang SK, Hong WS, Min YI et al. Incidence and prevalence of ulcerative colitis in the SongpaKangdong District, Seoul, Korea,19861997. J. Gastroenterol. Hepatol. 2000; 15: $1037-$ 42.
19) A Sood, V Midha, N Sood, et al.Punjab, North India.Incidence and prevalence of Ulcerative Colitis. Gut 2003 52: 1587-1590

20) Hanauer SB. Inflammatory bowel disease: epidemiology, pathogenesis, and therapeutic opportunities. Inflamm Bowel Dis 2006; 12 (Suppl 1): S3-S9.].

Correspondence Address: Dr. Shaneel Harsh, DM Residence IOM Kathmandu, Nepal E-mail: drshaneelharsh@gmail.com 